\title{
Article \\ Evaluation of Glycogen Storage Patients: Report of Twelve Novel Variants and New Clinical Findings in a Turkish Population
}

\author{
Melike Ersoy ${ }^{1}$, Bulent Uyanik ${ }^{2}$ and Asuman Gedikbasi ${ }^{3, *}$ \\ 1 Division of Pediatric Metabolic Diseases, Department of Pediatrics, Bakirkoy Dr. Sadi Konuk Training and \\ Research Hospital, University of Health Sciences, Istanbul 34093, Turkey; melike.ersoy@saglik.gov.tr \\ 2 Division of Medical Genetics, Department of Internal Medicine, Faculty of Medicine, \\ Bezmialem Foundation University, Istanbul 34093, Turkey; buyanik@bezmialem.edu.tr \\ 3 Division of Medical Genetics, Department of Pediatric Basic Sciences, Institute of Child Health, \\ Istanbul University, Istanbul 34104, Turkey \\ * Correspondence: asuman.gedikbasi@istanbul.edu.tr
}

Citation: Ersoy, M.; Uyanik, B.; Gedikbasi, A. Evaluation of Glycogen Storage Patients: Report of Twelve Novel Variants and New Clinical Findings in a Turkish Population. Genes 2021, 12, 1987. https:/ / doi.org/ 10.3390 /genes12121987

Academic Editor:

Hirokazu Takahashi

Received: 3 November 2021

Accepted: 7 December 2021

Published: 15 December 2021

Publisher's Note: MDPI stays neutral with regard to jurisdictional claims in published maps and institutional affiliations.

Copyright: (C) 2021 by the authors. Licensee MDPI, Basel, Switzerland. This article is an open access article distributed under the terms and conditions of the Creative Commons Attribution (CC BY) license (https:/ / creativecommons.org/licenses/by/ $4.0 /)$.
Abstract: Glycogen storage diseases (GSDs) are clinically and genetically heterogeneous disorders that disturb glycogen synthesis or utilization. Although it is one of the oldest inherited metabolic disorders, new genetic methods and long-time patient follow-ups provide us with unique insight into the genotype-phenotype correlations. The aim of this study was to share the phenotypic features and molecular diagnostic results that include new pathogenic variants in our GSD cases. Twenty-six GSD patients were evaluated retrospectively. Demographic data, initial laboratory and imaging features, and current findings of the patients were recorded. Molecular analysis results were classified as novel or previously defined variants. Novel variants were analyzed with pathogenicity prediction tools according to American College of Medical Genetics and Genomics (ACGM) criteria. Twelve novel and rare variants in six different genes were associated with the disease. Hearing impairment in two patients with GSD I, early peripheral neuropathy after liver transplantation in one patient with GSD IV, epilepsy and neuromotor retardation in three patients with GSD IXA were determined. We characterized a heterogeneous group of all diagnosed GSDs over a 5-year period in our institution, and identified novel variants and new clinical findings. It is still difficult to establish a genotype-phenotype correlation in GSDs.

Keywords: glycogen storage disease; genotype-phenotype; novel variants; new clinic findings

\section{Introduction}

Glycogen storage diseases [GSDs] are a large group of inherited metabolic diseases with abnormal storage or utilization of glycogen. They affect primarily the liver and muscle, followed by the nervous system, kidneys, intestine, and leukocytes [1]. The incidence of all forms of glycogen storage disease is $1 / 10,000$ [2]. Depending on the type of enzyme deficiency in tissue, it is classified as muscle or liver glycogenosis. However, both muscle and liver can be affected in some types [3]. The diagnosis of GSDs is based on the enzyme assay and/or molecular analysis as a result of the biochemical analysis and biopsy examination of the patients with characteristic signs [4]. GSDs have broad genetic heterogeneity and phenotypical variations. Some GSDs lead to death within the first years of life, whereas some remain asymptomatic for life. Genotype-phenotype correlation has been reported for some mutations in GSD patients [5]. Patients with late-onset or atypical presentation can experience a delay in diagnosis and proper treatment. Some unexpected clinical findings may accompany classical features [6]. The aim of this study was to characterize the phenotype of the followed GSDs over a 5-year period in our center, and to report novel variants. Thus, we contributed to knowledge on the phenotype-genotype correlation by reporting the new clinical findings we identified. 


\section{Materials and Methods}

The initial clinical and biochemical findings of the patients diagnosed in metabolism center of Bakirkoy Dr. Sadi Konuk Training and Research Hospital between January 2015 and June 2020 were evaluated retrospectively as a cross-sectional study. The study protocol was approved by the Institutional Ethics Committee (approved number: 2020/66; date: 22 March 2020). Written informed consent was obtained from all legal guardians before study enrollment.

Biochemical, clinical, and imaging data of the patients were obtained from the hospital electronic system and patient files. High-purity DNA was isolated from peripheral blood leukocytes using a DNA isolation kit (PureLink ${ }^{\mathrm{TM}}$ Genomic DNA Mini Kit, Invitrogen, CA, USA) following the manufacturer's protocol, in all patients. In order to elucidate the molecular etiology, two massive parallel-sequencing methods were used to identify variants that cause GSDs; targeted gene panel and clinical exome sequencing (CES). Twenty patients were examined by targeted gene-panel sequencing involving the use of a customized panel including 16 GSD-associated genes (GYS2, GYS1, G6PC, SLC37A4, AGL, GBE1, PYGM, PYGL, PFKM, PHKA2, PHKB, PHKG2, PHKA1, PGAM2, and PGM1). Six patients with unexplained liver and muscle enzyme elevation or neuromotor retardation were examined by Clinical Exome Sequencing (CES) using the Illumina Clinical-Exome Sequencing TruSight One Gene Panel. In both the panel and the CES, the libraries generated were sequenced with 250-bp paired-end reads using the Illumina MiSeq or Nextseq500 next-generation sequencing platforms. Detected variants were confirmed by conventional Sanger sequencing using the BigDye Terminator Cycle Sequencing kit (Applied Biosystems, Foster City, CA, USA) using both the patients' genomic DNA, and if available, that of their parents.

\section{Results}

\subsection{Demographic and Laboratory Findings}

Twenty-six patients diagnosed with GSD from 24 unrelated families were investigated. Demographic data of the patients are summarized in Table 1. The initial laboratory findings are shown in Table 2. As a result of molecular analysis, 12 novel pathogenic variations were detected; GYS2 c.607A $>$ G (p.Thr203Ala) and c.1307A $>C$ (p.Gln436Pro), G6PC c.562+1G>A (p.?), GBE1 c.1054G>C (p.Asp352His), PYGL c.1355G>T (p.Gly452Val), c.23801G>C p.(?), c.921_924del (p.His308Leufs*8), PHKA2 c.1978C >T (p.Leu660Phe), c.3028$2 \mathrm{~A}>\mathrm{G}$ (p.?), c.3201G >T (p.Trp1067Cys), PHKB exon 18-21 deletion (p.?), PHKA1 c.1963C >T (p.Arg655Cys) (Table 3).

Table 1. Demographic and clinical findings of the patients.

\begin{tabular}{|c|c|c|c|c|c|c|c|c|c|c|c|c|}
\hline ID & $\begin{array}{l}\text { GSD } \\
\text { Type }\end{array}$ & Gender & $\begin{array}{l}\text { Onset } \\
\text { (Month) }\end{array}$ & $\begin{array}{c}\text { Follow-Up } \\
\text { Time (Year) }\end{array}$ & Hypoglycemia & Liver & Muscle & Hearth & Kidney & $\begin{array}{l}\text { Short } \\
\text { Struc- } \\
\text { ture }\end{array}$ & $\begin{array}{l}\text { Mental } \\
\text { Retarda- } \\
\text { tion }\end{array}$ & $\begin{array}{l}\text { Additional } \\
\text { Finding }\end{array}$ \\
\hline P1 & GSD0 & $\mathrm{F}$ & 4 & 16 & + & - & - & - & - & - & - & - \\
\hline P2 & GSD0 & M & 6 & 7 & + & - & - & - & - & - & - & - \\
\hline P3 & GSD0 & $\mathrm{F}$ & 37 & 3 & + & - & - & - & - & - & - & - \\
\hline P4 & GSDIa & $\mathrm{F}$ & 2 & 5 & + & + & - & - & - & + & - & osteoporosis \\
\hline P5 & GSDIa & M & 1 & 4 & + & + & - & - & - & + & - & $\begin{array}{c}\text { congenital } \\
\text { hypothyiroidism }\end{array}$ \\
\hline P6 & GSDIa & F & 4 & 5 & + & + & - & - & + & + & - & $\begin{array}{l}\text { hearing loss, } \\
\text { osteoporosis }\end{array}$ \\
\hline P7 & GSDIa & M & 3 & 14 & + & + & - & - & + & + & - & $\begin{array}{l}\text { hearing loss, } \\
\text { osteoporosis }\end{array}$ \\
\hline P8 & GSDIa & M & 1 & 11 & + & + & - & - & + & + & - & $\begin{array}{l}\text { osteoporosis } \\
\text { neutropenia }\end{array}$ \\
\hline P9 & GSDIb & M & 1 & 5 & + & + & - & - & - & + & - & $\begin{array}{l}\text { aphthous } \\
\text { stomatitis }\end{array}$ \\
\hline P10 & GSDIII & $\mathrm{F}$ & 2 & 4 & + & + & + & - & - & - & - & - \\
\hline P11 & GSDIII & $\mathrm{F}$ & 12 & 1.5 & + & + & + & - & - & - & - & - \\
\hline
\end{tabular}


Table 1. Cont.

\begin{tabular}{|c|c|c|c|c|c|c|c|c|c|c|c|c|}
\hline ID & $\begin{array}{l}\text { GSD } \\
\text { Type }\end{array}$ & Gender & $\begin{array}{l}\text { Onset } \\
\text { (Month) }\end{array}$ & $\begin{array}{l}\text { Follow-Up } \\
\text { Time (Year) }\end{array}$ & Hypoglycemia & Liver & Muscle & Hearth & Kidney & $\begin{array}{l}\text { Short } \\
\text { Struc- } \\
\text { ture }\end{array}$ & $\begin{array}{l}\text { Mental } \\
\text { Retarda- } \\
\text { tion }\end{array}$ & $\begin{array}{l}\text { Additional } \\
\text { Finding }\end{array}$ \\
\hline P12 & GSDIII & M & 17 & 4 & + & + & + & - & - & + & - & - \\
\hline P13 & GSDIV & $\mathrm{F}$ & 9 & 7 & - & + & - & - & - & - & + & $\begin{array}{l}\text { liver } \\
\text { tranplantation, } \\
\text { neuropathy }\end{array}$ \\
\hline P14 & GSDIV & $\mathrm{F}$ & 22 & 0.5 & - & + & - & - & - & - & - & $\begin{array}{c}\text { liver } \\
\text { tranplantation }\end{array}$ \\
\hline P15 & GSDV & $\mathrm{M}$ & 25 & 0.25 & - & - & + & - & - & - & - & - \\
\hline P16 & GSDV & $\mathrm{F}$ & 28 & 0.5 & - & - & + & - & - & - & - & - \\
\hline P17 & GSDVI & M & 4 & 5 & + & + & + & - & - & + & - & - \\
\hline P18 & GSDVI & M & 7 & 5 & + & + & - & - & - & + & - & - \\
\hline P19 & GSDVI & $\mathrm{F}$ & 7 & 5 & + & + & - & - & - & + & - & - \\
\hline P20 & GSDVI & $\mathrm{F}$ & 30 & 3 & + & + & - & - & - & + & - & - \\
\hline P21 & GSDIXa & $\mathrm{M}$ & 9 & 1.5 & + & + & - & - & - & + & - & - \\
\hline P22 & GSDIXa & M & 10 & 0.5 & - & + & - & - & - & + & + & autism, seizure \\
\hline P23 & GSDIXa & M & 19 & 0.5 & - & + & - & + & - & + & + & - \\
\hline P24 & GSDIXa & M & 11 & 2 & - & + & - & - & - & - & + & seizure \\
\hline P25 & GSDIXb & M & 15 & 2 & - & + & + & - & - & + & - & - \\
\hline P26 & GSDIXd & M & 26 & 1 & - & + & + & - & - & - & - & thrombocytopenia \\
\hline
\end{tabular}

"+" (plus) means presence of the finding, " -" (minus) means absence of the finding.

Table 2. Initial laboratory and imaging features of patients.

\begin{tabular}{|c|c|c|c|c|c|c|c|c|c|c|c|c|c|}
\hline ID & Type & $\begin{array}{l}\text { Glycose } \\
\mathrm{mg} / \mathrm{dL}\end{array}$ & $\begin{array}{l}\text { AST } \\
\text { U/L }\end{array}$ & $\begin{array}{l}\text { ALT } \\
\text { IU/L }\end{array}$ & $\begin{array}{l}\text { CPK } \\
\text { U/L }\end{array}$ & $\begin{array}{l}\text { LDL } \\
\mathrm{mg} / \mathrm{dL}\end{array}$ & $\begin{array}{l}\text { HDL } \\
\mathrm{mg} / \mathrm{dL}\end{array}$ & $\begin{array}{c}\text { Cholesterol } \\
\mathrm{mg} / \mathrm{dL}\end{array}$ & $\begin{array}{l}\text { Triglyceride } \\
\text { mg/dL }\end{array}$ & $\begin{array}{c}\mathrm{AFP} \\
\mathrm{ng} / \mathrm{mL}\end{array}$ & $\begin{array}{l}\text { Lactate } \\
\mathrm{mg} / \mathrm{dL}\end{array}$ & Ketone & $\begin{array}{l}\text { Ultrasound } \\
\text { and/or ECHO }\end{array}$ \\
\hline P1 & GSD0 & 37 & 26 & 16 & 55 & 95 & 61 & 168 & 68 & 1 & 30 & + & normal \\
\hline P2 & GSD0 & 35 & 30 & 18 & 68 & 79 & 68 & 172 & 56 & 1 & 26 & ++ & normal \\
\hline P3 & GSD0 & 49 & 16 & 30 & 67 & 58 & 65 & 136 & 64 & 1 & 11 & + & normal \\
\hline P4 & GSDIa & 12 & 134 & 73 & 57 & 126 & 27 & 323 & 2007 & 2 & 65 & + & grade 1 steatosis \\
\hline P5 & GSDIa & 14 & 65 & 71 & 49 & 136 & 41 & 213 & 546 & 2 & 40 & ++ & hepatomegaly \\
\hline P6 & GSDIa & 9 & 282 & 133 & 67 & 149 & 23 & 341 & 1158 & 1 & 53 & +++ & $\begin{array}{l}\text { heterogeneity in } \\
\text { liver and kidney }\end{array}$ \\
\hline P7 & GSDIa & 16 & 257 & 305 & 97 & 171 & 13 & 304 & 1200 & 2 & 97 & + & $\begin{array}{l}\text { heterogeneity in } \\
\text { liver and kidney }\end{array}$ \\
\hline P8 & GSDIa & 73 & 197 & 187 & 67 & 184 & 44 & 284 & 944 & 1.5 & 35 & neg & $\begin{array}{l}\text { hepatomegaly, } \\
\text { heterogenity }\end{array}$ \\
\hline P9 & GSDIb & 20 & 62 & 45 & 76 & 94 & 19 & 167 & 267 & 1.2 & 26 & neg & grade 1 steatosis \\
\hline P10 & $\begin{array}{l}\text { GSD } \\
\text { III }\end{array}$ & 34 & 226 & 327 & 1760 & 138 & 12 & 225 & 370 & 1 & 43 & neg & $\begin{array}{c}\text { grade } 2 \text { steatosis } \\
\text { hepatomegaly }\end{array}$ \\
\hline P11 & GSDIII & 71 & 705 & 867 & 867 & 186 & 30 & 217 & 479 & 4.4 & 42 & neg & $\begin{array}{c}\text { grade } 1 \text { steatosis, } \\
\text { hepatomegaly } \\
\text { grade } 1\end{array}$ \\
\hline P12 & GSDIII & 23 & 160 & 123 & 424 & 145 & 8 & 234 & 471 & 41 & 25 & + & $\begin{array}{c}\text { heterogeneity, } \\
\text { hepatomegaly } \\
\text { nodular }\end{array}$ \\
\hline P13 & GSDIV & 74 & 317 & 137 & 54 & 96 & 28 & 139 & 75 & 13 & 12 & neg & $\begin{array}{l}\text { heterogeneous } \\
\text { liver } \\
\text { nodular }\end{array}$ \\
\hline P14 & GSDIV & 65 & 158 & 14 & 57 & 104 & 46 & 172 & 106 & 18 & 13 & neg & $\begin{array}{c}\text { heterogeneous in } \\
\text { liver }\end{array}$ \\
\hline P15 & GSDV & 86 & 50 & 29 & 556 & 78 & 45 & 139 & 69 & 0.8 & 15 & neg & normal \\
\hline P16 & GSDV & 100 & 33 & 18 & 318 & 95 & 38 & 178 & 69 & - & - & neg & normal \\
\hline P17 & GSDVI & 74 & 545 & 444 & 87 & 104 & 22 & 178 & 241 & 2 & 25 & + & hepatomegaly \\
\hline P18 & GSDVI & 48 & 193 & 78 & 69 & 72 & 29 & 124 & 115 & 1.9 & 26 & ++ & hepatomegaly \\
\hline P19 & GSDVI & 39 & 60 & 64 & 98 & 94 & 36 & 158 & 138 & 2.7 & 31 & + & hepatomegaly \\
\hline P20 & GSDVI & 59 & 74 & 78 & 89 & 112 & 39 & 125 & 67 & 1.7 & 12 & + & $\begin{array}{l}\text { grade } 1 \text { steatosis, } \\
\text { hepatomegaly }\end{array}$ \\
\hline P21 & GSDIXa & 45 & 225 & 189 & 356 & 153 & 17 & 224 & 276 & 1 & 12 & + & $\begin{array}{l}\text { hepatomegaly, } \\
\text { grade } 1 \text { steatosis }\end{array}$ \\
\hline P22 & GSDIXa & 56 & 199 & 111 & 525 & 107 & 33 & 159 & 98 & 2 & 38 & ++ & $\begin{array}{l}\text { hepatomegaly } \\
\text { hepatomagaly, }\end{array}$ \\
\hline P23 & GSDIXa & 65 & 86 & 98 & 215 & 164 & 45 & 198 & 218 & 1.2 & 15 & neg & $\begin{array}{l}\text { heterogenity, } \\
\text { hypertophic } \\
\text { CMP }\end{array}$ \\
\hline P24 & GSDIXa & 75 & 68 & 64 & 218 & 120 & 72 & 208 & 71 & - & 26 & neg & hepatomagaly \\
\hline P25 & GSDIXb & 78 & 74 & 50 & 562 & 89 & 61 & 169 & 76 & 5 & 11 & ++ & $\begin{array}{c}\text { grade } 1 \\
\text { heterogeneity }\end{array}$ \\
\hline P26 & GSDIXd & 67 & 80 & 84 & 292 & 76 & 48 & 138 & 67 & 1 & 9 & +++ & hepatomegaly \\
\hline
\end{tabular}

Abbreviations: AST: Aspartate transaminase, ALT: Alanine transaminase, CPK: Creatine phosphokinase, LDL: Low-density lipoproteincholesterol, HDL: High-density lipoprotein-cholesterol, AFP: Alpha-fetoprotein, ECHO: echocardiography. "+" (plus) means presence of the finding, "-" (minus) means absence of the finding. 
Table 3. Molecular assays of patients.

\begin{tabular}{|c|c|c|c|c|c|}
\hline ID & Type & Gene & Inheritence & Allele 1 & Allele 2 \\
\hline P1 & GSD0 & GYS2 & $\mathrm{AR}$ & c.607A >G p.Thr203Ala & c. $1145 \mathrm{G}>$ A p.(Gly382Glu) \\
\hline $\mathrm{P} 2$ & GSD0 & GYS2 & $\mathrm{AR}$ & c.607A>G p.Thr203Ala & c. $1145 \mathrm{G}>$ A p.(Gly382Glu) \\
\hline P3 & GSD0 & GYS2 & $\mathrm{AR}$ & c.1307A >C p.Gln436Pro & c.1307A >C p.Gln436Pro \\
\hline $\mathrm{P} 4$ & GSDIa & G6PC & $\mathrm{AR}$ & c. $247 \mathrm{C}>\mathrm{T}$ p.R83C & c. $247 \mathrm{C}>\mathrm{T}$ p.R83C \\
\hline P5 & GSDIa & G6PC & $\mathrm{AR}$ & c. $247 \mathrm{C}>\mathrm{T}$ p.R83C & c. $247 \mathrm{C}>\mathrm{T}$ p.R83C \\
\hline P6 & GSDIa & G6PC & $\mathrm{AR}$ & c. $562+1 \mathrm{G}>\mathrm{A}$ & c. $562+1 \mathrm{G}>\mathrm{A}$ \\
\hline P7 & GSDIa & G6PC & AR & c. $247 \mathrm{C}>\mathrm{T}$ p.Arg83Cys & c. $247 \mathrm{C}>\mathrm{T}$ p.Arg83Cys \\
\hline P8 & GSD1a & G6PC & $\mathrm{AR}$ & c. $247 \mathrm{C}>\mathrm{T}$ p.Arg83cys & c. $247 \mathrm{C}>\mathrm{T}$ p.Arg83cys \\
\hline P9 & GSDIb & SLC37A4 & $\mathrm{AR}$ & $\begin{array}{l}\text { c.1043_1044delCT } \\
\text { p.Pro348ArgfsTer5 }\end{array}$ & $\begin{array}{l}\text { c.1043_1044delCT } \\
\text { p.Pro348ArgfsTer5 }\end{array}$ \\
\hline P10 & GSD III & $A G L$ & AR & c.1019delA p.Gln340fs & c.1019delA p.Gln340fs \\
\hline P11 & GSDIII & $A G L$ & $\mathrm{AR}$ & c.1020del p.Glu340Aspfs*9 & c.1020del p.Glu340Aspfs*9 \\
\hline P12 & GSDIII & $A G L$ & $\mathrm{AR}$ & c. $4126 \mathrm{C}>\mathrm{T}$ p.G $\ln 1376$ & c. $4126 \mathrm{C}>\mathrm{T}$ p.G $\mathrm{ln} 1376$ \\
\hline P13 & GSDIV & GBE1 & AR & c.1492G>A p.Glu498Lys & c.1492G>A p.Glu498Lys \\
\hline P14 & GSDIV & GBE1 & AR & c.1054G >C p.Asp352His & c.1054G >C p.Asp352His \\
\hline P15 & GSDV & PYGM & AR & c.1A>G p.Met1Val & c.1A>G p.Met1Val \\
\hline P16 & GSDV & PYGM & $\mathrm{AR}$ & c.772+2_772+3delTG & c.772+2_772+3delTG \\
\hline P17 & GSDVI & PYGL & $\mathrm{AR}$ & c.1355G > T p.Gly452Val & c.1355G > T p.Gly452 Val \\
\hline P18 & GSDVI & PYGL & $\mathrm{AR}$ & c.2380-1G >C IVS19_1G >C & c.2380-1G >C IVS19_1G >C \\
\hline P19 & GSDVI & PYGL & AR & c. $2380+1 G>C$ IVS19+1G $>C$ & c. $2380+1 G>C$ IVS19+1G $>C$ \\
\hline P20 & GSDVI & PYGL & AR & c.921_924del p.His308Leufs*8 & c.921_924del p.His308Leufs*8 \\
\hline P21 & GSDIXa & PH KA2 & $X L$ & c.3614C > T p.Pro1205Leu & c.3614C>T p.Pro1205Leu \\
\hline P22 & GSDIXa & PHKA2 & $\mathrm{XL}$ & c.1978C $>$ T p.Leu660Phe & c.1978C $>$ T p.Leu660Phe \\
\hline $\mathrm{P} 23$ & GSDIXa & PHKA2 & $X \mathrm{~L}$ & c. $3028-2 A>G$ & c. $3028-2 A>G$ \\
\hline P24 & GSDIXa & PHKA2 & $\mathrm{XL}$ & c.3201G > T p.Trp1067Cys & c.3201G > T p.Trp1067Cys \\
\hline P25 & GSDIXb & PHKB & $\mathrm{AR}$ & Exon18_21 deletion & Exon18_21 deletion \\
\hline P26 & GSDIXd & PHKA1 & $\mathrm{XL}$ & c. 1963 C > T p.Arg655Cys & c. 1963 C > T p.Arg655Cys \\
\hline
\end{tabular}

Abbreviations: AR: autosomal recessive, AD: autosomal dominant, XL: X-linked. The novel variants are shown in bold.

\subsection{Clinical Findings}

- $\quad$ P1-P3-GSD 0: P1 and P2 (two siblings) had symptomatic hypoglycemia, whereas P3 had asymptomatic hypoglycemia The mean age at diagnosis was $15.67 \pm 23.33$ months.

- P4-P9-GSDI: All six patients had typical clinical and laboratory features (hepatomegaly, hypoglycemia, lactic acidosis, hyperuricemia, hypercholesterolemia, and hypertriglyceridemia, and neutropenia for GSDIb-P9). Four patients had severe osteoporosis (P4, P6, P7, P8). Three patients (P6, P7, P8) had renal involvement including parenchymal heterogeneity and enlargement in kidneys with microalbuminuria despite good metabolic control. None of the patients developed chronic renal failure. Dialysis and transplantation were not required. Two (P6, P7) had nonfamilial sensorineural-type hearing loss. Congenital hypothyroidism was found in one GSDI patient (P5) (Table 1). The mean age at diagnosis was $2 \pm 1.26$ months.

- P10-P12-GSD III: Three patients were presented with typical signs of hypoglycemia, myopathy, and hepatopathy. Short stature developed only in P12. The mean age at diagnosis was $10.3 \pm 7.63$ months.

- P13-P14-GSD Type IV: Both patients underwent living donor liver transplantation at the age of 3 and 2 years, respectively, due to severe liver failure. Persistent mild neuromotor retardation and peripheral sensory neuropathy were detected after transplantation in P13. The mean age at diagnosis was $15.5 \pm 9.19$ months.

- P15-P16-GSD Type V: Both patients had mild muscle enzyme elevation with muscle pain and fatigue. None of them had any rhabdomyolysis attacks. The mean age at diagnosis was $26.5 \pm 2.12$ months.

- $\quad$ P17-P20-GSD Type VI: All patients presented with mild-to-moderate hepatomegaly, short stature, and ketotic hypoglycemia. The mean age at diagnosis was $6 \pm 1.23$ months. 
- P21-26-GSD Type IX: All patients had hepatic involvement. Additionally, short stature was detected in three (P21, P22, P23), and hypertrophic cardiomyopathy was detected in one patient (P23). Psychomotor retardation was prominent in three patients (P22, P23, P24). P22 and P24 had epilepsy. Autism spectrum findings were determined in P22. The mean age at diagnosis was $15 \pm 6.54$ months.

\section{Discussion}

We presented the clinical features and results of molecular analysis of 26 GSD patients followed in our center for five years. We reported the new clinical findings and novel pathogenic variants that we observed in our study. To the best of our knowledge, early peripheral neuropathy after liver transplantation in GSD IV, and psychomotor retardation, seizure, autism signs and hypertrophic cardiomyopathy in GSD IXa, are the first to be reported in the literature. Hearing impairment in GSD I is also rarely reported.

In our study, two novel variants of GYS2 associated with hepatic GSD0 [7,8] were detected in three patients; (c.1307A>C p.Gln436Pro) (P3, homozygous) and [c.607A>G p.(Thr203Ala)] (P1,2, heterozygous). Both siblings (P1,P2) had good blood-glucose control, with frequent protein-rich meals and nighttime feedings of uncooked cornstarch. They had normal growth and development. On the other hand, P3 had no clinical findings until the age of five, and was diagnosed with incidentally detected hypoglycemia. These two novel mutations might be related to a mild phenotype, and should be confirmed in further studies.

Another novel mutation of G6PC associated with GSDIa was detected in a patient; c.562+1G >A (P7, homozygous). The most striking finding was the bilateral sensorineural hearing impairment that was detected in two of our patients with different mutations (one with common, previously defined; c.247C > T and one with novel; c.562+1G>A, P6, P7, respectively) [9,10]. Iwanicka-Pronicka et al. [11] reported hearing impairment "at birth" in four (2 GSDIa; 2 GSDIb) out of 40 GSDI cases (20 patients with each subtype). The underlying mechanism has not been yet determined. Hearing impairment was determined when P6 was 6 months old and P7 was 18 months old; both of them passed newborn hearing screening tests and have normal brain MRI (magnetic resonance imaging), EEG (electroencephalogram), and neurocognitive development; they had a cochlear implant at the age of 1 and 2, respectively. Both have mild disarticulation and speech disturbance. As their hearing was normal at birth, auditory dysfunction gene panel or whole exome sequencing (WES) was not performed. For this reason, it would be appropriate to perform hearing evaluation in order to detect hearing loss early in GSD type 1 patients. Short stature and osteoporosis are remarkable findings among patients at any age, and may be due to inappropriate metabolic control, poor nutrition, the effects of lactic acidosis, or accompanying endocrinological problems (hypogonadism) [12-14]. The occurrence of osteoporosis in all of our patients, except the younger (P5), can be attributed to the above-mentioned factors. However, the short stature was also determined at P5. Kidneys were affected in three cases (P6-P8). The size and echogenicity of both kidneys increased in grade 1 . One case has microalbuminuria, and none of them have impaired renal function tests. Renal involvement seems to be a complication that develops over time in advanced ages. The first sign of kidney involvement can be detected on ultrasound before clinical signs develop.

In our three patients, previously reported mutations were detected in the GSDIIIrelated ALG gene (P10-12) (Table 3) [15,16]. While all of the cases had liver and muscle involvement, heart involvement was not observed during the follow-up.

Two missense mutations were identified in GBE1-related GSDIV (one previously defined; c.1492G>A p.E498K and one novel; c.1054G>C p.Asp352His, P13, P14, respectively). P14 typically presented with hypotonia, myopathy, and hepatopathy. There is no treatment for this case other than liver transplantation [17]. Apart from that, it also causes a complex neurological condition called "Adult Polyglucosan Body Disease" (APBD), which shows symptoms after the fifth decade of life. It presents a variable combination of cognitive 
impairment, pyramidal tetraparesis, peripheral neuropathy, cerebellar dysfunction, and extrapyramidal signs [18,19]. Our P13 patient had mild developmental delay and peripheral sensory neuropathy at the age of six, which is an interesting early finding. To the best of our knowledge, there is no reported case in the literature that has both severe hepatic and neuromuscular involvement at this age. Performing neurological follow-up of patients with GBE1 mutation from an earlier age will provide a chance for early detection of neurological findings.

We found a novel pathogenic variation in PYMG -related GSDV; c.772+2_772+3delTG (P16, homozygous). P17 had a previously reported mutation (Table 3). GSDV leads to exercise-induced myalgia and recurrent myoglobinuria, which may result in acute renal failure. No rhabdomyolysis attack was observed in either of our patients with appropriate treatment. Three novel pathogenic PYGL mutations related GSDVI were identified in four patients; c.1355G >T (p.Gly452Val) (P17, homozygous), c.2380-1G>C p.(?) (P18, P19, homozygous) and c.921_924del (p.His308Leufs*8) (P20, homozygous). GSDVI may present with different combinations of findings including hepatomegaly, mild-to-moderate hypoglycemia, hyperlactatemia, hyper-transaminasemia, and short stature [20,21]. Short stature with normal neuromotor development should be a warning sign for GSD type VI. All four patients achieved a normal growth rate with appropriate treatment. All the clinical signs and biochemical parameters were improved.

GSDIX is a group of glycogenoses caused by hepatic phosphorylase kinase deficiency, a hexadecameric enzyme comprising four copies each of four unique subunits encoded by four different genes; PHKA1, PHKA2, PHKB, and PHKG2 [20,22]. Five out of six patients had novel mutated genes as follows; in PHKA2 c.1978C $>\mathrm{T}$ (p.Leu660Phe) (P22, homozygous) c.3028-2A $>\mathrm{G}$ (p.?) (P23, homozygous), c.3201G $>\mathrm{T}$ (p.Trp1067Cys) (P24, homozygous), in PHKB exon 18_21 deletion (p.?) (P25, homozygous), in PHKA1 c.1963C >T (p.Arg655Cys) (P26, homozygous). The most common findings are hepatomegaly, short stature, delay in motor development, the elevation of transaminases, cholesterol, and triglyceride, fasting hyperketosis, and hypoglycemia. Neurological involvement is only in the form of mild motor-development delay in the GSDIX phenotype (6). Conspicuously, the clinical presentation in our GSDIX group was different from the literature. Unexpected new findings in our patients were marked psychomotor retardation (P22, P23, P24), seizure (P22, P24), autism signs (P22) and hypertrophic cardiomyopathy (P23). Therefore, GSD was not considered according to clinical presentation at admission, and exome sequencing was performed instead of the GSD panel test. The diagnoses of these patients were achieved by CES because of these different presentations. No additional pathologic variants were found in bioinformatic analyses to explain these findings.

\section{Conclusions}

This study identifies 12 novel mutations as well as diverse and new clinical features in GSD patients. It seems difficult to establish phenotype-genotype correlations in all types of GSDIX. To the best of our knowledge, hearing impairment in GSD I, early peripheral neuropathy after liver transplantation in GSD IV, and psychomotor retardation, seizure, autism signs and hypertrophic cardiomyopathy in GSD IXa can be considered as newly determined, rare and unexcepted findings.

\section{Limitations of the Study}

Although there is a high number of 26 patients in terms of general glycogen storage diseases for one single center, the small size of GSDs' subgroups is the limitation of the study in terms of interpretation.

Author Contributions: Conceptualization, M.E.; methodology, M.E. and A.G.; software, M.E.; validation, M.E., A.G. and B.U.; formal analysis, M.E., B.U. and A.G.; investigation, M.E. and A.G.; resources, M.E. and B.U.; data curation, M.E. and B.U.; writing — original draft preparation, M.E., A.G. and B.U.; writing—review and editing, M.E. and A.G.; visualization, M.E.; supervision, A.G.; 
project administration, M.E.; funding acquisition, none. All authors have read and agreed to the published version of the manuscript.

Funding: This research received no external funding.

Institutional Review Board Statement: The study was conducted according to the guidelines of the Declaration of Helsinki, and approved by the Institutional Ethics Committee of Bakirkoy Dr. Sadi Konuk Training and Research Hospital (protocol code 2020/66; and date of approval 22 March 2020).

Informed Consent Statement: Informed consent was obtained from all subjects involved in the study. Written informed consent has been obtained from the patient(s) to publish this paper.

Data Availability Statement: The data presented in this study are available on request from the corresponding author. The data are not publicly available due to privacy.

Conflicts of Interest: No conflict of interest was declared by the authors.

\section{References}

1. Özen, H. Glycogen storage diseases: New perspectives. World J. Gastroenterol. 2007, 13, 2541-2553. [CrossRef] [PubMed]

2. Priya, S.; Kishnani, D.K.; Yuan-Tsong, C. Glycogen Storage Diseases. Online Metabolic and Molecular Bases of Inherited Diseasel; McGraw-Hill: New York, NY, USA, 2001; Chapter 17.

3. DiMauro, S.; Bruno, C. Glycogen storage diseases of muscle. Curr. Opin. Neurol. 1998, 11, 477-484. [CrossRef] [PubMed]

4. Wolsdorf, J.I.; Holm, I.A.; Weinstein, D.A. Glycogen storage disease: Phenotypic, genetic, and biochemical characteristics, and therapy. Endocrinol. Metab. Clin. 1999, 28, 802-824.

5. Ley-Martos, M.; Salado-Reyes, M.J.; Espinosa-Rosso, R.; Solera-García, J.; Jiménez-Jiménez, L. Variability in the clinical presentation of Pompe disease: Development following enzyme replacement therapy. Rev. De Neurol. 2015, 61, 416-420.

6. Smith, C.; Care4Rare Canada Consortium; Dicaire, M.-J.; Brais, B.; La Piana, R. Neurological Involvement in Glycogen Storage Disease Type IXa due to PHKA2 Mutation. Can. J. Neurol. Sci. J. Can. Des. Sci. Neurol. 2020, 47, 400-403. [CrossRef]

7. Laberge, A.M.; Mitchell, G.A.; Van De Werve, G.; Lambert, M. Long-term follow-up of a new case of liver glycogen synthase deficiency. Am. J. Med. Genet. 2003, 120A, 19-22. [CrossRef]

8. Gitzelmann, R.; Spycher, M.A.; Feil, G.; Müller, J.; Seilnacht, B.; Stahl, M.; Bosshard, N.U. Liver glycogen synthase deficiency: A rarely diagnosed entity. Eur. J. Pediatr. 1996, 155, 561. [CrossRef] [PubMed]

9. Stenson, P.D.; Mort, M.; Ball, E.V.; Shaw, K.; Philips, A.; Cooper, D.N. The Human Gene Mutation Database: Building a comprehensive mutation repository for clinical and molecular genetics, diagnostic testing and personalized genomic medicine. Hum. Genet. 2014, 133, 1-9. [CrossRef]

10. Chou, J.Y.; Jun, H.S.; Mansfield, B. Type I glycogen storage diseases: Disorders of the glucose-6-phosphatase/glucose-6-phosphate transporter complexes. J. Inherit. Metab. Dis. 2015, 38, 511-519. [CrossRef]

11. Iwanicka-Pronicka, K.; Trubicka, J.; Pronicki, M.; Szymanska, E.; Ciara, E.; Rokicki, R.; Wortmann, S. Hearing loss as a newly recognized symptom of GSD type I. A clinical report of four unrelated Polish patients. Res. Sq. 2020. [CrossRef]

12. Smit, G.P.A. The long-term outcome of patients with glycogen storage disease type Ia. Eur. J. Nucl. Med. Mol. Imaging 1993, 152, 52-55. [CrossRef] [PubMed]

13. Talente, G.M.; Coleman, R.A.; Alter, C.; Baker, L.; Brown, B.I.; Cannon, R.A.; Chen, Y.-T.; Crigler, J.F.; Ferreira, P.; Haworth, J.C.; et al. Glycogen Storage Disease in Adults. Ann. Intern. Med. 1994, 120, 218-226. [CrossRef] [PubMed]

14. Cabrera-Abreu, J.; Crabtree, N.J.; Elias, E.; Fraser, W.; Cramb, R.; Alger, S. Bone mineral density and markers of bone turnover in patients with glycogen storage disease types I, III and IX. J. Inherit. Metab. Dis. 2004, 27, 1-9. [CrossRef]

15. Shen, J.; Bao, Y.; Liu, H.M.; Lee, P.; Leonard, J.V.; Chen, Y.T. Mutations in exon 3 of the glycogen debranching enzyme gene are associated with glycogen storage disease type III that is differentially expressed in liver and muscle. J. Clin. Investig. 1996, 98, 352-357. [CrossRef]

16. Parvari, R.; Moses, S.; Shen, J.; Hershkovitz, E.; Lerner, A.; Chen, Y.-T. A Single-Base Deletion in the 3'-Coding Region of Glycogen-Debranching Enzyme Is Prevalent in Glycogen Storage Disease Type IIIA in a Population of North African Jewish Patients. Eur. J. Hum. Genet. 1997, 5, 266-270. [CrossRef]

17. Schene, I.F.; Korenke, C.G.; Huidekoper, H.H.; van der Pol, L.; Dooijes, D.; Breur, J.M.P.J.; Biskup, S.; Fuchs, S.A.; Visser, G. Glycogen Storage Disease Type IV: A Rare Cause for Neuromuscular Disorders or Often Missed? JIMD Rep. 2019, 45, 99-104.

18. Naddaf, E.; Kassardjıan, C.D.; Kurt, Y.G.; Akman, H.O.; Windebank, A.J. Adult polyglucosan body disease presenting as a unilateral progressive plexopathy. Muscle Nerve 2016, 53, 976-981. [CrossRef] [PubMed]

19. Schröder, J.M.; May, R.; Shin, Y.S.; Sigmund, M.; Nase-Hüppmeier, S. Juvenile hereditary polyglucosan body disease with complete branching enzyme deficiency (type IV glycogenosis). Acta Neuropath. 1993, 85, 419-430. [CrossRef]

20. Kishnani, P.S.; on behalf of the ACMG Work Group on Diagnosis and Management of Glycogen Storage Diseases Type VI and IX; Goldstein, J.; Austin, S.L.; Arn, P.; Bachrach, B.; Bali, D.S.; Chung, W.K.; El-Gharbawy, A.; Brown, L.M.; et al. Diagnosis and management of glycogen storage diseases type VI and IX: A clinical practice resource of the American College of Medical Genetics and Genomics (ACMG). Genet. Med. 2019, 21, 772-789. [CrossRef] [PubMed] 
21. Aeppli, T.R.; Rymen, D.; Allegri, G.; Bode, P.K.; Häberle, J. Glycogen storage disease type VI: Clinical course and molecular background. Eur. J. Nucl. Med. Mol. Imaging 2019, 179, 405-413. [CrossRef] [PubMed]

22. Hidaka, F.; Sawada, H.; Matsuyama, M.; Nunoi, H. A novel mutation of the PHKA2 gene in a patient with X-linked liver glycogenosis type 1. Pediatr. Int. 2005, 47, 687-690. [CrossRef] [PubMed] 